\title{
Correlation of IL-1 and HB-EGF with endometrial receptivity
}

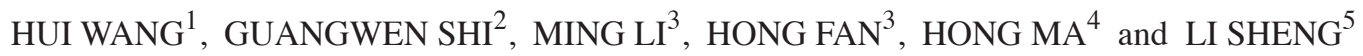 \\ ${ }^{1}$ Department of Reproductive Medicine, Yantaishan Hospital, Yantai, Shandong 264001; Departments of ${ }^{2}$ Obstetrics and \\ ${ }^{3}$ Nursing and ${ }^{4}$ Mingzhu Community Service Station, People's Hospital of Zhangqiu, Jinan, Shandong 250200; \\ ${ }^{5}$ Department of Clinical Laboratory, Yantai Yuhuangding Hospital, Yantai, Shandong 264000, P.R. China
}

Received March 6, 2018; Accepted September 4, 2018

DOI: $10.3892 /$ etm. 2018.6840

\begin{abstract}
Fluctuations of interleukin-1 $\beta$ (IL-1 $\beta$ ) and heparinbinding epidermal growth factor (HB-EGF) in endometrial receptivity were detected. Seventy-two patients receiving in vitro fertilization-embryo transfer (IVF-ET) for the first time in Yantaishan Hospital from July 2015 to September 2015 due to infertility were selected. The serum and follicular fluid of patients in ovulation-promoting cycle were collected; the levels of IL-1 $\beta$ and HB-EGF in serum and follicular fluid were detected via enzyme-linked immunosorbent assay (ELISA), and the levels of serum estradiol (E2), progesterone (P), follicle stimulating hormone (FSH) and luteinizing hormone ( $\mathrm{LH})$ were detected. The endometria in early follicular phase and middle luteal phase were collected, and the mRNA expression levels of IL-1 $\beta$ and HB-EGF were evaluated by reverse transcription quantitative polymerase chain reaction (RT-qPCR). Patients were divided into two groups, and the implantation group $(n=33)$ and the non-implantation group $(n=39)$, according to whether embryos were implanted and the general data. In IVF-ET, the levels of IL-1 $\beta$ and HB-EGF in follicular fluid and middle luteal phase, the level of serum IL-1 $\beta$ on human chorionic gonadotropin (HCG) day and embryo transfer (ET) day, the levels of E2, FSH and LH on HCG day in implantation group were obviously higher than those in non-implantation group ( $\mathrm{p}<0.05)$; the level of P on ET day in implantation group was significantly higher than that in non-implantation group $(p<0.05)$; the expression levels of IL-1 $\beta$ and HB-EGF in endometrium in middle luteal phase in implantation group were higher than those in non-implantation group $(\mathrm{p}<0.05)$; the expression levels of IL-1 $\beta$ and HB-EGF in endometrium were positively correlated with the levels of E2 and P, and endometrial thickness $(\mathrm{p}<0.05)$. IL-1 $\beta$ and HB-EGF may improve the endometrial receptivity to embryo, thus affecting
\end{abstract}

Correspondence to: $\mathrm{Dr} \mathrm{Li}$ Sheng, Department of Clinical Laboratory, Yantai Yuhuangding Hospital, 20 Yudong Road, Yantai, Shandong 264000, P.R. China

E-mail: sw95sc@163.com

Key words: endometrial receptivity, interleukin-1 $\beta$, heparin-binding epidermal growth factor, in vitro fertilization-embryo transfer the embryo implantation rate, through the synergistic action with E2 and P, so they may be the indexes of predicting the IVF-ET pregnancy outcome.

\section{Introduction}

Endometrial receptivity refers to the receptivity of maternal endometrium to blastocysts. The complex process that the blastocysts in the activated state invade into the endometrium and interact with one another after the positioning, adhesion and implantation is known as embryo implantation (1). This state has a certain temporal and spatial specificity, so it is known as 'implantation window', which generally appears in the midsecretive phase of endometrium on the 20th to $23 \mathrm{rd}$ day in menstrual cycle (namely the 7th-9th day after ovulation) (2). The endometrium in the embryo implantation window phase, on the one hand, creates a suitable micro-environment for the embryonic development and implantation, and, on the other hand, regulates embryos to reach the most suitable place for implantation under the guidance of cytokines (3). Although the extensive development of assisted reproductive technology has brought the gospel to many patients with infertility, and the relevant operation techniques have significantly optimized the number and quality of embryos, the embryo implantation rate is still as low as about $20-30 \%$ (4), and about two thirds of patients received failed embryo implantation repeatedly due to poor endometrial receptivity (5). Studies have found that a variety of cytokines and grow th factors act synergistically in the mother-fetal crosstalk process, such as interleukin-1 $\beta$ (IL-1 $\beta$ ) and heparin-binding epidermal growth factor (HB-EGF) $(6,7)$. Therefore, the study on relevant factors involved in endometrial receptivity is expected to be a key to improving the success rate of embryo implantation. In this study, the contents of IL-1 $\beta$ and HB-EGF in serum, follicular fluid and endometrium of infertile patients at different time were detected, and their correlations with endometrial receptivity were investigated, so as to elucidate their values in predicting the endometrial receptivity in in vitro fertilization-embryo transfer (IVF-ET).

\section{Patients and methods}

Patient selection. A total of 72 patients who receiving IVF-ET for the first time in Department of Reproductive 
Medicine, Yantaishan Hospital (Yantai, China) from July 2015 to September 2015 due to infertility were selected. All patients had a menstrual cycle of 28-30 days, and did not receive steroid hormone therapy in the past three months. Controlled ovarian hyperstimulation was performed using the long protocol developed by our center, and the follicles, endometrial thickness and implantation were monitored via vaginal B ultrasound. Gonadotropin ( $\mathrm{Gn}$ ) was withdrawn when the diameter (d) of at least three dominant follicles were $\geq 16 \mathrm{~mm}$ in bilateral ovaries, $\mathrm{d}$ of two dominant follicles $\geq 17 \mathrm{~mm}$ and diameter of one dominant follicle $\geq 18 \mathrm{~mm}$; human chorionic gonadotropin (HCG) was injected on that night, and the estradiol (E2), progesterone (P), follicle stimulating hormone (FSH) and luteinizing hormone (LH) in blood were detected; at 34-36 h after injection of HCG, oocytes were retrieved via vaginal $\mathrm{B}$ ultrasound. $\mathrm{P}$ ( $80 \mathrm{mg} / \mathrm{day})$ was injected on the day of embryo transfer (ET), and $\beta-\mathrm{HCG}$ in blood was detected after 2 weeks. $\beta$-HCG $>25 \mathrm{mIU} / \mathrm{ml}$ indicated the biochemical pregnancy, and pregnant women continued to receive the luteal support. At 5 weeks after transfer, patients were divided into implantation group $(n=33)$ and non-implantation group $(n=39)$ according to whether they had clinical pregnancy. P continued to be applied and was decreased gradually until 3 months after pregnancy. This study was approved by the Ethics Committee of Yantaishan Hospital, and the patients signed the informed consent.

\section{Methods}

General conditions. The age, menstrual history, body mass index (BMI), duration of infertility, causes of infertility, Gn dosage (n), number of retrieved oocytes (n), number of transferred embryos (n), number of high-quality embryos (n) and number of frozen embryos (n) were recorded. The weight of the patients in fasting state was weighed, and the height of each patient was also measured. BMI $=$ weight $/$ height $^{2}$.

Collection of endometrial tissues. In the natural cycle, the ovulation was monitored via vaginal B ultrasound combined with urine test paper; the fasting blood was drawn in the early morning in middle luteal phase (namely the 5th-7th day after ovulation) for simulated ET and endometrial test. A small number of endometria were stored in the refrigerator at $-80^{\circ} \mathrm{C}$ for detection. At the same time, the pathological examination was performed to confirm the mid-secretive phase of endometrium. Endometrial repair was performed in the early follicular phase (the 3rd day in menstrual period), and a small number of endometria were stored in the refrigerator at $-80^{\circ} \mathrm{C}$ for detection.

Serum collection. Before receiving the IVF-ET, the fasting blood was collected on the 3rd day in the menstrual cycle (D3), day of injecting HCG (HCG day), day of oocyte retrieval (OR day) and the day of ET (ET day), the serum was separated via high-speed centrifugation at 1,000 $\mathrm{x} g$ at $4^{\circ} \mathrm{C}$ for $10 \mathrm{~min}$ and placed in the refrigerator at $-20^{\circ} \mathrm{C}$ for detection. The levels of serum IL-1 $\beta$ (cat. no. EHC002b.96, Neobioscience, Shenzhen, China) and HB-EGF (cat. no. RJ12420, Renjiebio, Nanchang, China) on D3, HCG day, OR day and ET day were measured via double-antibody sandwich enzyme-linked immunosorbent assay (ELISA). The E2, P, FSH and LH levels on D3, HCG day and ET day were measured via radioimmunoassay.
Table I. Primer sequences.

\begin{tabular}{ll}
\hline Molecule & \multicolumn{1}{c}{ Primer $\left(5^{\prime} \rightarrow 3^{\prime}\right)$} \\
\hline IL-1 $\beta$ & F: AAT GAT GGC TTA TTA CAG TGG C \\
& R: TGT AGT GGT GGT CGG AGA TT \\
HB-EGF & F: ACA AGG AGG AGC ACG GGA AAA G \\
& R: CGA TGA CCA GCA GAC AGA CAG ATG \\
$\beta$-actin & F: CAC AAG TCA CAC TTC ACA \\
& R: CTA TCA CCT CGT GCT CT
\end{tabular}

F, forward; R, reverse; IL-1 $\beta$, interleukin-1 $\beta$; HB-EGF, heparin-binding epidermal growth factor.

Table II. Comparisons of general conditions between implantation group and non-implantation group.

\begin{tabular}{lrrrr}
\hline & $\begin{array}{l}\text { Implantation } \\
\text { group }(\mathrm{n}=33)\end{array}$ & $\begin{array}{c}\text { Non-implantation } \\
\text { group }(\mathrm{n}=39)\end{array}$ & t-value & P-value \\
\hline Age (years) & $30.12 \pm 4.32$ & $29.56 \pm 4.51$ & 0.81 & 0.31 \\
$\begin{array}{l}\text { Duration of } \\
\text { infertility (years) }\end{array}$ & $4.92 \pm 3.12$ & $4.84 \pm 3.73$ & 0.63 & 0.65 \\
BMI (kg/m $)$ & $22.01 \pm 2.45$ & $21.71 \pm 2.14$ & 0.54 & 0.69 \\
$\begin{array}{l}\text { Gn dosage (n) } \\
\text { No. of retrieved }\end{array}$ & $37.76 \pm 8.31$ & $38.22 \pm 9.17$ & 0.71 & 0.62 \\
$\begin{array}{l}\text { oocytes (n) } \\
\text { No. of transferred } \\
\text { embryos (n) }\end{array}$ & $2.14 \pm 0.53$ & $2.03 \pm 0.65$ & 1.20 & 0.24 \\
$\begin{array}{l}\text { No. of high-quality } \\
\text { embryos (n) }\end{array}$ & $8.41 \pm 4.63$ & $8.32 \pm 4.58$ & 0.98 & 0.27 \\
$\begin{array}{l}\text { No. of frozen } \\
\text { embryos (n) }\end{array}$ & $5.46 \pm 5.12$ & $3.97 \pm 4.26$ & 1.25 & 0.19 \\
\hline
\end{tabular}

BMI, body mass index.

Collection of follicular fluid. When the follicular development reached the standard, appropriate sedation was performed at 30 min before ovulation, and the bladder was emptied; under the lithotomy position, oocytes were retrieved via culdocentesis under the guidance of vaginal B ultrasound; $3 \mathrm{ml}$ follicular fluid not washed was retained (the contaminated fluid was discarded), and the supernatant was taken via high-speed centrifugation at $1,000 \mathrm{x} \mathrm{g}$ at $4^{\circ} \mathrm{C}$ for $10 \mathrm{~min}$ and placed at $-20^{\circ} \mathrm{C}$ for detection. The levels of IL- $1 \beta$ and HB-EGF in follicular fluid (FF) on OR day were measured via double-antibody sandwich ELISA in strict accordance with the instructions. Three wells were repeated for each specimen, and the average was taken.

All the patients received transvaginal ultrasound to detect the embryonic development and endometrial thickness. The measurement errors were excluded, each index was measured 3 times, and the average was taken.

Reverse transcription quantitative polymerase chain reaction $(R T-q P C R)$. RT-qPCR was determined as follows: Total RNA extraction, synthesis of the first cDNA chain and 
Table III. IL-1 $\beta$ and HB-EGF levels in serum and follicular fluid of patients in the two groups.

\begin{tabular}{|c|c|c|c|c|c|}
\hline \multirow[b]{2}{*}{ Group } & \multicolumn{4}{|c|}{ Serum } & \multirow[b]{2}{*}{$\mathrm{FF}$} \\
\hline & D3 & HCG day & OR day & ET day & \\
\hline \multicolumn{6}{|c|}{ Implantation group $(n=33)$} \\
\hline $\mathrm{IL}-1 \beta(\mathrm{ng} / \mathrm{ml})$ & $17.26 \pm 7.49$ & $162.86 \pm 53.27$ & $71.21 \pm 24.65$ & $39.46 \pm 28.18$ & $67.02 \pm 24.20$ \\
\hline HB-EGF (pg/ml) & $312.25 \pm 255.13$ & $323.34 \pm 267.17$ & $337.28 \pm 263.49$ & $361.10 \pm 285.26$ & $350.42 \pm 285.26$ \\
\hline \multicolumn{6}{|c|}{ Non-implantation group $(n=39)$} \\
\hline IL-1 $\beta(\mathrm{ng} / \mathrm{ml})$ & $15.32 \pm 7.37$ & $82.86 \pm 35.34$ & $33.91 \pm 14.53$ & $60.46 \pm 25.12$ & $39.08 \pm 18.26$ \\
\hline HB-EGF (pg/ml) & $272.28 \pm 195.06$ & $288.43 \pm 207.62$ & $295.29 \pm 213.87$ & $285.14 \pm 205.83$ & $230 \pm 285.26$ \\
\hline
\end{tabular}

IL-1 $\beta$, interleukin-1 $\beta$; HB-EGF, heparin-binding epidermal growth factor; D3, 3rd day in menstrual cycle; HCG day, day of injecting HCG; OR day, day of oocyte retrieval; ET day, day of embryo transfer; FF, follicular fluid.

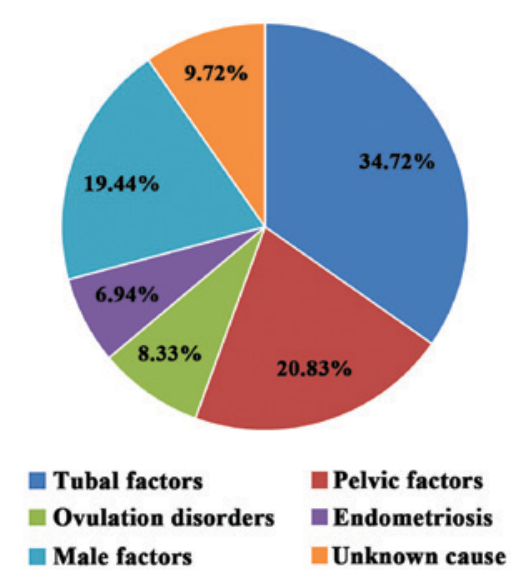

Figure 1. Pathogenesis of infertility patients.

RT-qPCR. The procedures were according to the instructions of TRIzol kit (Invitrogen; Thermo Fisher Scientific, Inc., Carlsbad, CA, USA), cDNA kit (Toyobo Life Science, Osaka, Japan) and SYBR-Green PCR kit (code no. QPK-201, Toyobo Life Science), respectively. Amplification system: $12.5 \mu \mathrm{l}$ SYBR mixture, $2 \mu \mathrm{lcDNA}, 0.5 \mu \mathrm{l}$ forward primer, $0.5 \mu 1$ reverse primer (Table I), addition of $\mathrm{ddH}_{2} \mathrm{O}$ until $25 \mu \mathrm{l}$. Reaction procedure: $42^{\circ} \mathrm{C}$ for $20 \mathrm{~min}, 95^{\circ} \mathrm{C} \times 5 \min \left(95^{\circ} \mathrm{C} 15 \mathrm{sec}, 55^{\circ} \mathrm{C} \times 15 \mathrm{sec}\right.$, $72^{\circ} \mathrm{C} \times 20 \mathrm{sec}$ ) for 40 cycles, $95^{\circ} \mathrm{C} \times 1 \mathrm{~min}, 55^{\circ} \mathrm{C} \times 30 \mathrm{sec}$ and $95^{\circ} \mathrm{C} \times 30 \mathrm{sec}$. The experiment was repeated 3 times to reduce the error and bias, and $\beta$-actin gene was selected as the internal reference. The data were analyzed using the Real-time detector (ABI-7500; New York, NY, USA), and the relative expression levels of IL-1 $\beta$ and HB-EGF mRNA in endometrial tissues were presented using $2^{-\Delta \Delta C q}(8)$.

Statistical analysis. Statistical Product and Service Solutions (SPSS) 18.0 (SPSS Inc., Chicago, IL, USA) software was used for analysis. Measurement data in normal distribution are presented as mean \pm SD. Student's t-test or post hoc test after one-way analysis of variance in SPSS were used to analyze the differences between the groups. Tukey's was the post hoc test used following one-way analysis of variance. Pearson's correlation analysis was performed for the correlation between indexes. $\mathrm{P}<0.05$ was considered to indicate a statistically significant difference.

\begin{abstract}
Results
Etiological analysis of infertile patients. Among the 72 patients, 25 cases (34.72\%) suffered from infertility due to tubal factors (tubal inflammation, history of tubal ligation and congenital tubal abnormality), 15 cases (20.83\%) due to pelvic factors, 6 cases $(8.33 \%)$ due to ovulation disorders, 5 cases (6.94\%) due to endometriosis, 14 cases (19.44\%) due to male factors (sperm abnormality: Oligo-astheno-teratospermia, necrospermia and azoospermia), and 7 cases $(9.72 \%)$ due to unknown causes. Tubal factors ranked first (Fig. 1).
\end{abstract}

Comparisons of general conditions between the two groups of patients. There were no significant differences in the age, duration of infertility, BMI, Gn dosage, number of retrieved oocytes, number of transferred embryos, number of highquality embryos and number of frozen embryos between the two groups of patients $(\mathrm{p}>0.05)$. The baseline data were uniform and comparable (Table II).

Comparisons of IL-1 $\beta$ and HB-EGF levels in serum and follicular fluid at each time-point between the two groups of patients. The HB-EGF levels changes are not significant in the early follicular phase, on HCG day, OR day and ET day of the two groups of patients ( $p>0.05$ ). The level of HB-EGF in follicular fluid in implantation group was higher than that in non-implantation group, and the difference was statistically significant $(\mathrm{t}=2.76, \mathrm{p}=0.01)$. There was no statistically significant difference in the IL-1 $\beta$ level on D3 between the two groups ( $p>0.05)$. The level of serum IL-1 $\beta$ on HCG day in implantation group was significantly increased compared with that on OR day or ET day $(\mathrm{p}<0.05)$. The level of serum IL-1 $\beta$ on HCG day in non-implantation group was higher than those on OR day and ET day $(p<0.05)$, but it was still significantly lower than that in implantation group $(\mathrm{p}<0.05)$. The level of serum IL-1 $\beta$ on ET day in non-implantation group was significantly increased compared with that in implantation group $(p<0.05)$. The level of IL-1 $\beta$ in follicular fluid in implantation group was significantly higher than that in nonimplantation group $(p<0.05)$. The level of IL-1 $\beta$ on OR day in implantation group was significantly higher than that on D3 ( $<<0.05)$ (Table III). 
Table IV. Expression levels of IL-1 $\beta$ and HB-EGF mRNA in early follicular phase and middle luteal phase in the two groups of patients.

\begin{tabular}{|c|c|c|c|c|c|c|}
\hline Group & Early follicular phase & t-value & P-value & Middle luteal phase & t-value & P-value \\
\hline \multicolumn{7}{|l|}{ IL-1 $\beta$ mRNA expression level } \\
\hline Implantation group $(\mathrm{n}=33)$ & $0.35 \pm 0.18$ & 1.45 & 0.09 & $0.92 \pm 0.20$ & 6.41 & 0.01 \\
\hline Non-implantation group $(n=39)$ & $0.23 \pm 0.09$ & & & $0.54 \pm 0.17$ & & \\
\hline \multicolumn{7}{|l|}{ HB-EGF mRNA expression level } \\
\hline Implantation group $(n=33)$ & $0.61 \pm 0.24$ & 1.62 & 0.08 & $2.43 \pm 0.59$ & 7.59 & 0.00 \\
\hline Non-implantation group $(n=39)$ & $0.50 \pm 0.17$ & & & $1.12 \pm 0.58$ & & \\
\hline
\end{tabular}

IL-1 $\beta$, interleukin-1 $\beta$; HB-EGF, heparin-binding epidermal growth factor.

Table V. Comparison of serum hormone levels at different time-points between the two groups of patients.

\begin{tabular}{|c|c|c|c|c|}
\hline Group & $\mathrm{E} 2(\mathrm{pg} / \mathrm{ml})$ & $\mathrm{P}(\mathrm{ng} / \mathrm{ml})$ & FSH (mIU/ml) & $\mathrm{LH}(\mathrm{mIU} / \mathrm{ml})$ \\
\hline \multicolumn{5}{|c|}{ Implantation group $(n=33)$} \\
\hline D3 & $56.12 \pm 10.23$ & $0.65 \pm 0.46$ & $4.28 \pm 1.47$ & $3.13 \pm 1.39$ \\
\hline HCG day & $2893.52 \pm 1068.34$ & $0.86 \pm 0.57$ & $24.93 \pm 9.08$ & $139.06 \pm 53.45$ \\
\hline ET day & $896.47 \pm 428.51$ & $27.58 \pm 13.94$ & $13.87 \pm 11.95$ & $17.01 \pm 5.28$ \\
\hline \multicolumn{5}{|c|}{ Non-implantation group $(n=39)$} \\
\hline D3 & $55.34 \pm 11.82$ & $0.63 \pm 0.48$ & $4.31 \pm 1.50$ & $3.32 \pm 1.27$ \\
\hline HCG day & $1538.26 \pm 786.26$ & $0.80 \pm 0.51$ & $12.98 \pm 7.02$ & $101.64 \pm 32.16$ \\
\hline ET day & $894.54 \pm 378.38$ & $21.56 \pm 7.25$ & $10.62 \pm 9.59$ & $15.17 \pm 7.24$ \\
\hline
\end{tabular}

E2, estradiol; P, progesterone; FSH, follicle stimulating hormone; LH, luteinizing hormone; D3, 3rd day in menstrual cycle; HCG day, day of injecting HCG; ET day, day of embryo transfer.

Table VI. Pearson's correlation analysis of IL-1 $\beta$ and HB-EGF expression levels in endometrium in middle luteal phase with endometrial thickness and $\mathrm{E} 2$ and $\mathrm{P}$.

\begin{tabular}{lccc}
\hline Variables & $\begin{array}{c}\text { Endometrial } \\
\text { thickness }(\mathrm{mm})\end{array}$ & $\mathrm{E} 2(\mathrm{pg} / \mathrm{ml})$ & $\mathrm{P}(\mathrm{ng} / \mathrm{ml})$ \\
\hline IL-1 $\beta$ in endometrium & & & \\
$\mathrm{r}$ & 0.83 & 0.35 & 0.42 \\
$\mathrm{p}$ & 0.00 & 0.03 & 0.02 \\
HB-EGF in endometrium & & & \\
$\mathrm{r}$ & 0.72 & 0.29 & 0.36 \\
$\mathrm{p}$ & 0.01 & 0.04 & 0.03 \\
\hline
\end{tabular}

IL-1 $\beta$, interleukin-1 $\beta$; HB-EGF, heparin-binding epidermal growth factor; E2, estradiol; P, progesterone.

Expression levels of $I L-1 \beta$ and HB-EGF in early follicular phase and middle luteal phase in the two groups of patients. The expression levels of IL-1 $\beta$ and HB-EGF in the early follicular phase in implantation group were significantly higher than those in non-implantation group, but the differences were not statistically significant $(\mathrm{p}<0.05)$. The expression levels of IL-1 $\beta$ and HB-EGF in endometrium in middle luteal phase in

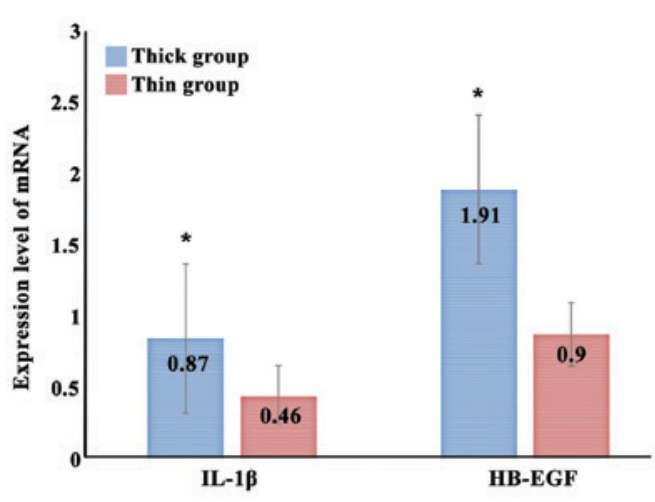

Figure 2. Expression levels of IL-1 $\beta$ and HB-EGF in middle luteal phase in different endometrial thickness. The mRNA expression level of IL-1 $\beta$ in the endometrium of the two groups in middle luteal phase has a statistically significant difference, ${ }^{*} \mathrm{p}<0.05$ vs. intimal thickness $<9 \mathrm{~mm}$; the mRNA expression level of HB-EGF in the endometrium of the two groups in middle luteal phase has a statistically significant difference, $" \mathrm{p}<0.05$ vs. intimal thickness $<9 \mathrm{~mm}$.

implantation group were higher than those in non-implantation group $(\mathrm{p}<0.05)$ (Table IV).

Comparison of serum hormone levels at different time-points between the two groups of patients. The serum E2, P, FSH and LH levels in the two groups of patients on D3 had no statistically 
significant differences ( $\mathrm{p}>0.05)$, and the basic endocrine level was consistent and comparable. The levels of E2, FSH and LH on HCG day in implantation group were significantly higher than those in non-implantation group $(\mathrm{p}<0.05)$, but there was no statistically significant difference in the P level $(\mathrm{p}>0.05)$. The P level on ET day in implantation group was obviously higher than that in non-implantation group $(\mathrm{p}<0.05)$, but there were no statistically significant differences in the levels of E2, FSH and LH (Table V).

Expression levels of $I L-1 \beta$ and HB-EGF in middle luteal phase in different endometrial thickness. There were 56 out of 72 patients with the endometrial thickness $\geq 9 \mathrm{~mm}$ (thick group), and 16 patients with the endometrial thickness $<9 \mathrm{~mm}$ (thin group). The mRNA expression levels of IL-1 $\beta$ in middle luteal phase in the thick group and the thin group were $0.87 \pm 0.19$ and $0.48 \pm 0.16$, respectively. The expression of IL- $1 \beta$ mRNA in the thick group was significantly increased compared with that in the thin group $(\mathrm{t}=-2.68, \mathrm{P}<0.01)$. The mRNA expression levels of HB-EGF in middle luteal phase in the thick group and the thin group were $1.91 \pm 0.86$ and $0.90 \pm 0.28$, respectively. The expression of HB-EGF mRNA in the thick group was significantly increased compared with that in the thin group $(\mathrm{t}=-3.12$, $\mathrm{P}<0.05$ ) (Fig. 2).

Correlation analysis of $I L-1 \beta$ and $H B-E G F$ expression levels in endometrium in middle luteal phase with endometrial thickness and E2 and P. The expression level of IL-1 $\beta$ in the endometrium was positively correlated with the endometrial thickness and E2 and P levels $(r=0.83, p<0.01 ; r=0.35, p<0.05$; $r=0.42, p<0.05)$. The expression level of HB-EGF was also positively correlated with the endometrial thickness and $\mathrm{E} 2$ and $\mathrm{P}(\mathrm{r}=0.72, \mathrm{p}<0.05 ; \mathrm{r}=0.29, \mathrm{p}<0.05 ; \mathrm{r}=0.36, \mathrm{p}<0.05)($ Table VI).

\section{Discussion}

Reasons for infertility in patients receiving IVF. Over the past 30 years, with the marketing of the assisted fertility technique and the vigorous development of derivative techniques, the assisted reproduction technique informtion has reached the majority of infertility patients. In terms of reasons for infertility, it was found in this study that the fallopian tube factor ranks first (34.72\%), including the tubal non-specific inflammation, history of tubal ligation, and congenital abnormalities of fallopian tube; pelvic factors; the male factors (sperm abnormality: Oligo-astheno-teratospermia, necrospermia and azoospermia) are the main factors of intracytoplasmic sperm injection (ICSI); the endometriosis ranks second; ovulation disorders; and there are other causes of infertility, including chromosomal abnormalities, male ejaculatory disorders and genital malformations; and unknown causes (9). In this study, it was found that the number of patients receiving fresh ET due to ovulation disorders was small (8.33\%). Patients with ovulation disorders are often patients with polycystic ovary syndrome (PCOS) and susceptible to ovarian hyper-stimulation syndrome (OHSS). Compared with fresh ET, the frozen ET has a higher live birth rate, and a lower abortion rate (10).

$I L-1 \beta$ and endometrial receptivity. IL-1 was first discovered in 1972 by Gray et al (11) from the mononuclear cell culture supernatant, which can promote the thymocyte proliferation, so it is named lymphocyte activation factor. After 7 years, it was officially renamed IL-1. IL-1 is a polypeptide consisting of two receptor agonists, IL-1 $\alpha$ and IL-1 $\beta$, and one IL-1 receptor antagonist (IL-1r $\alpha$ ). IL-1 receptors have two subtypes, namely the type I (IL-1RtI) and type II (IL-1RtII). In recent years, the role of IL-1 $\beta$ in reproductive activity has attracted increasing attention and is thought to be associated with endometrial receptivity (12). IL-1 $\beta$ regulates the reproduction of women through systemic and local effects: 1) It directly acts on genital center through the blood circulation; 2) it induces local expression in ovarian, uterine and follicular fluid, and regulates the reproductive function by promoting the $\mathrm{P}$ secretion and affecting the activity of $\mathrm{Na}^{+} / \mathrm{K}^{+}$-ATPase $(13,14)$. It is currently recognized that IL-1 $\beta$ in blood is derived from macrophages, but the theory of cell origin of IL-1 $\beta$ in follicular fluid is not clear, such as plasma ultrafiltrate or interstitial cells, follicular cell and granulocyte $(15,16)$. In this study, it was found that the serum IL-1 $\beta$ level in women was significantly increased in follicular phase and before ovulation (HCG day). The document analysis showed that at IL- $1 \beta>80 \mathrm{pg} / \mathrm{ml}$, the ET capacity was significantly increased (17); when the serum IL-1 $\beta$ concentration was increased, E2 was also significantly increased, and they had a positive correlation ( $\mathrm{r}=0.35, \mathrm{p}=0.03)$; E2 plays a vital role in follicular growth and development and endometrial growth; the change rate of serum IL-1 $\beta$ concentration in implantation group was similar to that of blood $\mathrm{LH}$; the IL-1 $\beta$ concentration was gradually increased with oocyte maturation and reached the peak on the day before ovulation (HCG day), indicating that IL-1 $\beta$ may be involved in follicular growth, development, maturation and induced ovulation, which can improve the fertilization rate and embryo quality, thereby improving the implantation rate. This study showed that there was only a small amount of IL-1 $\beta$ in serum on D3, but its level was significantly increased in luteal phase after ovulation; the concentration of serum IL-1 $\beta$ was positively correlated with progesterone $(\mathrm{P})(\mathrm{r}=0.42, \mathrm{p}=0.02)$, suggesting that the serum IL-1 $\beta$ is closely related to $\mathrm{P}(18)$. The lowconcentration $\mathrm{P}$ promotes IL-1 $\beta$ gene expression, while the high-concentration of $\mathrm{P}$ inhibits the expression (19), but the critical concentration of $\mathrm{P}$ in regulating the IL-1 $\beta$ gene expression remains unclear and needs further study. Simón et al (20) found that IL-1 $\beta$, IL-1RtI and IL-1r $\alpha$ can be detected in the human endometrium, endometrial fluid, embryo and endometrial-embryo interface, which can block the IL-1RtI in rat endometrium, and inhibit the gamete implantation. So far, how IL-1 regulates the endometrial tolerance is not yet clear. Some scholars believe that IL-1 increases the epithelial adhesion to the blastocyst by increasing the expression of epithelial cell adhesion molecules, thereby regulating the endometrial receptivity (21). IL-1 is found to be upregulated at 7 and 9 days in ovulation stage, consistent with the 'implantation window' stage. Moreover, IL-1 $\beta$ is involved in the immune tolerance in placental formation and promotes the growth of embryos via regulating the expression of $\mathrm{NF}-\mathrm{\kappa B}$ (22). In this study, it was found that IL-1 receptor antagonists act on the 'implantation window' stage of endometrium, terminating the embryo implantation process (22). In addition, studies have shown that (23) IL-1 may trigger angiogenesis, thus promoting the embryonic growth, through affecting the expression of HCG. 
$H B-E G F$ and endometrial receptivity. HB-EGF is one of the members of epidermal growth factor family and binds to the HB-EGF receptor on the surface of embryo and endometrium under the catalysis of heparan sulfate proteoglycan to play a role in mediating the 'molecular crosstalk' between embryo and intima (24). HB-EGF plays different roles in follicular development, ovulation, embryo implantation and early development (25), which has become a research hotspot in the field of reproduction. Studies have found that HB-EGF mRNA is expressed in the endometrium (mainly expressed in the luminal epithelium and glandular epithelium, and reaches the peak in the mid-secretive stage or at 20 days in menstrual cycle), early pregnancy villi, decidua and placenta in the entire menstrual cycle $(26,27)$. The results of RT-qPCR in this study showed that the expression of HB-EGF mRNA in endometrium in middle luteal phase was significantly higher than that in early follicular phase $(\mathrm{p}<0.05)$, suggesting that the significantly increased HB-EGF mRNA in the endometrium in middle luteal phase may be closely related to the embryo implantation. Studies have revealed that HB-EGF may be maternal, which attracts blastocysts, promotes the development of blastocysts, adheres to the blastocyst and repairs endometrial function in the process of implantation (28). The results of this study showed that the relative expression of HB-EGF mRNA in implantation group in implantation window was significantly higher than that in non-implantation group $(\mathrm{p}<0.05)$. Maternal HB-EGF lacks causes the embryo implantation delay, and destroys the synchronous endometrial and embryonic development, leading to pregnancy failure (29). Thus, HB-EGF is expected to be one of the potential predictors of IVF-ET pregnancy outcome. In addition, it was found in this study that in the IVF cycle, the embryo implantation rate in patients with endometrial thickness of $\geq 9 \mathrm{~mm}$ was significantly higher than that with thickness $<9 \mathrm{~mm}(\mathrm{p}<0.05)$, and the results were consistent with the findings of Sher and Fisch (30). The expression level of HB-EGF was positively correlated with the endometrial thickness $(r=0.72, p=0.01)$, indicating that HB-EGF mRNA may mediate the endometrial growth, thus affecting the IVF pregnancy outcome. It was found in this study that HB-EGF could be detected in serum throughout the menstrual cycle, but there were no statistically significant differences in the expression levels on D3, OR day and ET day $(p>0.05)$. In view of many factors affecting the HB-EGF in serum, it is more important to evaluate the expression of HB-EGF in endometrium and follicular fluid, instead of evaluating the endometrial receptivity via serum HB-EGF. The cytokines in the microenvironment of follicular fluid will have direct effects on the development, maturation and discharge of oocytes and the embryogenesis after fertilization. It was found in this study that the level of HB-EGF in follicular fluid in implantation group was significantly higher than that in non-implantation group $(\mathrm{p}<0.05)$, indicating that the expression level of HB-EGF in follicular fluid is related to the embryo implantation and affects the outcome of pregnancy.

The expression of IL-1 $\beta$ and HB-EGF in endometrium show the periodic regularity; they are highly expressed in middle luteal phase and implantation group, but lowly expressed in early follicular phase and non-implantation group. Moreover, the expression levels of IL-1 $\beta$ and HB-EGF are positively correlated with the endometrial thickness, and levels of serum E2 and P, indicating that IL- $1 \beta$ and HB-EGF may improve the endometrial receptivity to embryo, thus affecting the embryo implantation rate, through the synergistic action with $\mathrm{E} 2$ and $\mathrm{P}$, so they may be the indexes of predicting the IVF-ET pregnancy outcome.

\section{Acknowledgements}

Not applicable.

\section{Funding}

No funding was received.

\section{Availability of data and material}

All data generated or analyzed during this study are included in this published study.

\section{Authors' contributions}

HW contributed to the conception of the study and the performance of the statistical analysis with constructive discussions. GS helped with the collection of endometrial tissues. ML contributed significantly to data analysis and manuscript preparation; HF and HM performed the data analyses. LS contributed significantly to the data analysis and study preparation. All authors read and approved the final study.

\section{Ethics approval and consent to participate}

This study was approved by the Ethics Committee of Yantaishan Hospital (Yantai, China). Informed consents were signed by the patients or guardians.

\section{Patient consent for publication}

Not applicable.

\section{Competing interests}

The authors declare that they have no competing interests.

\section{References}

1. Norwitz ER, Schust DJ and Fisher SJ: Implantation and the survival of early pregnancy. N Engl J Med 345: 1400-1408, 2001.

2. Lim HJ and Dey SK: HB-EGF: A unique mediator of embryouterine interactions during implantation. Exp Cell Res 315: 619-626, 2009.

3. Valdez-Morales FJ, Gamboa-Domínguez A, Vital-Reyes VS, Cruz JC, Chimal-Monroy J, Franco-Murillo Y and Cerbón M: Changes in receptivity epithelial cell markers of endometrium after ovarian stimulation treatments: Its role during implantation window. Reprod Health 12: 45, 2015.

4. Lédée-Bataille N, Laprée-Delage G, Taupin JL, Dubanchet S, Frydman R and Chaouat G: Concentration of leukaemia inhibitory factor (LIF) in uterine flushing fluid is highly predictive of embryo implantation. Hum Reprod 17: 213-218, 2002.

5. Scalici J, Laughlin BB, Finan MA, Wang B and Rocconi RP: The trend towards minimally invasive surgery (MIS) for endometrial cancer: An ACS-NSQIP evaluation of surgical outcomes. Gynecol Oncol 136: 512-515, 2015. 
6. Huang HY, Wen Y, Kruessel JS, Raga F, Soong YK and Polan ML: Interleukin (IL)-1beta regulation of IL-1beta and IL-1 receptor antagonist expression in cultured human endometrial stromal cells. J Clin Endocrinol Metab 86: 1387-1393, 2001.

7. Stavreus-Evers A, Aghajanova L, Brismar H, Eriksson H, Landgren BM and Hovatta O: Co-existence of heparin-binding epidermal growth factor-like growth factor and pinopodes in human endometrium at the time of implantation. Mol Hum Reprod 8: 765-769, 2002.

8. Livak KJ and Schmittgen TD: Analysis of relative gene expression data using real-time quantitative PCR and the 2(-Delta Delta C(T)) Method. Methods 25: 402-408, 2001.

9. Kintiraki E, Papakatsika S, Kotronis G, Goulis DG and Kotsis V: Pregnancy-induced hypertension. Hormones (Athens) 14: 211-223, 2015

10. Chen ZJ, Shi Y, Sun Y, Zhang B, Liang X, Cao Y, Yang J, Liu J, Wei $\mathrm{D}$, Weng N, et al: Fresh versus frozen embryos for infertility in the polycystic ovary syndrome. N Engl J Med 375: 523-533, 2016.

11. Grey ST, Csizmadia V and Hancock WW: Differential effect of tumor necrosis factor-alpha on thrombomodulin gene expression by human monocytoid (THP-1) cell versus endothelial cells. Int J Hematol 67: 53-62, 1998.

12. Lédée N, Dubanchet S, Oger P, Meynant C, Lombroso R, Ville Y and Chaouat G: Uterine receptivity and cytokines: New concepts and new applications. Gynecol Obstet Invest 64: 138-143, 2007.

13. Tobai $\mathrm{H}$ and Nishiya I: Nitric oxide mediates inhibitory effect of interleukin-1beta on estrogen production in human granulosaluteal cells. J Obstet Gynaecol Res 27: 53-59, 2001.

14. Qinglei L, Jiang N, Shuling B and Lan Y: Effect of interleukin-1 $\beta$ on progesterone production and sodium-potassium adenosine triphosphatase activity by rat luteal cell in vitro. J Reprod Med 9 : $88-91,2000$.

15. Austgulen R, Arntzen KJ, Vatten LJ, Kahn J and Sunde A: Detection of cytokines (interleukin-1, interleukin-6, transforming growth factor-beta) and soluble tumour necrosis factor receptors in embryo culture fluids during in-vitro fertilization. Hum Reprod 10: 171-176, 1995.

16. Takacs P and Kauma S: The expression of interleukin-1 alpha, interleukin-1 beta, and interleukin-1 receptor type I mRNA during preimplantation mouse development. J Reprod Immunol 32: 27-35, 1996.

17. Gonzalez RR and Leavis P: Leptin upregulates beta 3-integrin expression and interleukin-1beta, upregulates leptin and leptin receptor expression in human endometrial epithelial cell cultures. Endocrine 16: 21-28, 2001

18. Machelon V, Nome F, Durand-Gasselin I and Emilie D: Macrophage and granulosa interleukin-1 beta mRNA in human ovulatory follicles. Hum Reprod 10: 2198-2203, 1995.
19. Díaz Flores M, Ortega-Camarillo C, Rosales-Torres AM, BaizaGutman LA and Hicks JJ: Nitric oxide as main effector in the interleukin-1 system in ovulation. Gac Med Mex 137: 291-302, 2001 (In Spanish).

20. Simón C, Piquette GN, Frances A and Polan ML: Localization of interleukin-1 type I receptor and interleukin-1 beta in human endometrium throughout the menstrual cycle. J Clin Endocrinol Metab 77: 549-555, 1993

21. Bourdiec A and Akoum A: Embryo implantation: Role of interleukin 1 family members. Med Sci (Paris) 30: 644-650, 2014 (In French).

22. Geisert R, Fazleabas A, Lucy M and Mathew D: Interaction of the conceptus and endometrium to establish pregnancy in mammals: Role of interleukin 1ß. Cell Tissue Res 349: 825-838, 2012.

23. Bourdiec A, Shao R, Rao CV and Akoum A: Human chorionic gonadotropin triggers angiogenesis via the modulation of endometrial stromal cell responsiveness to interleukin 1: A new possible mechanism underlying embryo implantation. Biol Reprod 87: 66, 2012

24. Jessmon P, Leach RE and Armant DR: Diverse functions of HBEGF during pregnancy. Mol Reprod Dev 76: 1116-1127, 2009.

25. Umata T: Mechanism for activation of heparin-binding EGF-like growth factor induced by stimuli. J UOEH 26: 85-97, 2004 (In Japanese)

26. Birdsall MA, Hopkisson JF, Grant KE, Barlow DH and Mardon HJ: Expression of heparin-binding epidermal growth factor messenger RNA in the human endometrium. Mol Hum Reprod 2: 31-34, 1996.

27. Leach RE, Khalifa R, Ramirez ND, Das SK, Wang J, Dey SK, Romero R and Armant DR: Multiple roles for heparin-binding epidermal growth factor-like growth factor are suggested by its cell-specific expression during the human endometrial cycle and early placentation. J Clin Endocrinol Metab 84: 3355-3363, 1999.

28. Stavreus-Evers A, Koraen L, Scott JE, Zhang P and Westlund P Distribution of cyclooxygenase-1, cyclooxygenase-2, and cytosolic phospholipase A2 in the luteal phase human endometrium and ovary. Fertil Steril 83: 156-162, 2005.

29. Armant DR, Wang J and Liu Z: Intracellular signaling in the developing blastocyst as a consequence of the maternalembryonic dialogue. Semin Reprod Med 18: 273-287, 2000.

30. Sher G and Fisch JD: Effect of vaginal sildenafil on the outcome of in vitro fertilization (IVF) after multiple IVF failures attributed to poor endometrial development. Fertil Steril 78: 1073-1076, 2002.

This work is licensed under a Creative Commons Attribution-NonCommercial-NoDerivatives 4.0 International (CC BY-NC-ND 4.0) License. 